\title{
Analysis of the Music and Cultural Relationship of "Mountain Flower" in Liupan Mountain of Ningxia
}

\author{
Xiangyong Zhang \\ Music and Dance Academy, Northern University for Nationalities, Yinchuan, China
}

Keywords: Liupan Mountain, mountain flowers, music, culture.

\begin{abstract}
Liupan Mountain "Mountain flower" is a kind of high-rise folk song popular in the southern part of Ningxia, due to the long history of multi-ethnic, multi-cultural social environment and Ningxia unique geographical style, Liupan Mountain "Mountain flower" to grow and develop. "Mountain flowers" in the music structure has obvious national characteristics, is the local ethnic groups is the culture in the continuous running after the concrete embodiment, and Ningxia region social environment, historical background, traditional customs, living habits are inseparable. This paper analyzes the musical characteristics and cultural characteristics of "Mountain flower" by analyzing the music characteristics and structural characteristics of "Mountain flower" in Liupan Mountain, and explored the music connotation and cultural heritage of "Mountain flower" in Liupan Mountain, and explored the relationship between music and culture of "Mountain flower" of the relationship, is conducive to Liupan Mountain "Mountain flower" the world of intangible cultural heritage protection and heritage.
\end{abstract}

\section{Introduction}

Flowers, commonly known as "mountain song", "wild song", is singing in the wild a high-end folk songs, full of rich flavor of life, although its birthplace in Gansu Linxia, but spread throughout the northwest plateau, and with the local Cultural integration, the formation of distinctive schools, such as Gansu's "Hezhou flowers", "Lotus flowers", Qinghai, "Qinghai flowers" and so on, Liupan Mountain "Mountain flowers" is one of the unique genre of high-chamber folk songs [1].

Liupan Mountain "mountain flower" sung the main body is Hui, mainly popular in southern Ningxia (Xiji, Haiyuan, Guyuan, Pengyang, Tongxin and other poor counties, collectively referred to as "the West Sea solid"). This piece of land is the ancient Silk Road must be the main road. From ancient times to the present, it is the blend of the northern minority and the Central Plains, which is influenced by the profound culture of the Central Plains and the cultural essence of the ethnic groups in the western region, the structure of the vast land is complex, both from the mainland to move here to the Hui, and there are Ming and Qing Dynasties since many times from here to reclamation immigration [2]. Therefore, the culture here has shown a Hui-based, the national culture blend, infiltration of the diverse style, which makes Liupan Mountain "Mountain flowers", has a clear geographical characteristics and unique charm. This paper analyzes the musical characteristics and cultural characteristics of "Mountain flowers" by analyzing the music characteristics and structural characteristics of "Mountain flowers" in Liupan Mountain, and explored the music connotation and cultural heritage of "Mountain flowers" in Liupan Mountain, and explored the relationship between music and culture of "mountain flower" The relationship between the Liupan Mountain "Mountain flowers" music protection and cultural heritage has important positive significance.

\section{Liupan Mountain "Mountain flowers" origin and development}

The Ningxia Hui Autonomous Region is located in the middle and upper reaches of the Yellow River in the northwest of China, with a latitude range of $35^{\circ} 14^{\prime} \mathrm{N} \sim 39^{\circ} 23^{\prime} \mathrm{N}$, large span of north and south, longitude range of $104^{\circ} 17^{\prime} \mathrm{E} \sim 107^{\circ} 39^{\prime} \mathrm{E}$. In China's natural zoning, Ningxia cross-eastern monsoon region and northwest arid area, southwest near the Qinghai-Tibet region, roughly in China's three major natural areas of the intersection, transition zone. From the geological and 
geomorphological point of view, Ningxia is located in China's geological, geomorphic "north and south axis" in the northern section of the North China block, Alashan platform and Qilian Mountains between the fold, southern Ningxia Liupan Mountain from north to north, Mountains, South Huashan, West Huashan and other intermittent, the Loess Plateau is divided into two [3]. Ningxia Hui Autonomous Region east of Shaanxi Province, west, north of Inner Mongolia Autonomous Region, the southern and Gansu Province is connected, since ancient times is the Central Plains, West through the Western Regions, north of the desert, the south to the north to the frequent areas. Ningxia religion as Ningxia main ethnic Hui, the people believe in Islam, in Ningxia Hui neighborhoods, built in different forms of buildings and different sizes of the mosque more than 3,000 seats, in addition to Islam, Ningxia there are Buddhism, Catholicism, Christianity, Taoism And other religions, all kinds of religions in Ningxia are treated equally, the normal religious activities of the masses are protected, and various religious people live in Ningxia for a long time. It is because of the long history of multi-ethnic, multi-cultural social environment and Ningxia unique geographical customs, Liupan Mountain "Mountain flowers" was born and thrive.

Liupan Mountain "mountain flower" development and musicians are between the growth is complementary, such as "mountain flowers" and the famous musician Wang Luobin had once because of a chance to forged a bond. It was dusk in 1937, Wang Luo Bin with the "Northwest Anti-enemy service regiment" to reach the foot of the Liupan Mountain car shop. At night, from the rhythm of the rain came a burst of high Kangxiao light, wearing a cloud-like ancient style. Wang Luobin was deeply attracted. After inquiring, the singer is the owner of the car shop "five plum", is known as the "flower" singer. Wang Luobin was infected by her song, and then they often vowed to return. Dusk, the sun after the rain, the boss learned that Wang Luobin soon to leave, sang a year before the farewell here to send the West to sing the "Liupan Mountain order." The song is simple and moving, Wang Luobin soul was strongly shocked, he had to go to Paris to study music, but in the Liupan Mountain to hear the "five plum" singing folk songs, that the music of the Holy Land in the Northwest Wilderness [4]. Since then, he walked into a colorful folk song world, and western folk songs forged a bond, and life dedicated to the creation and dissemination of Western folk songs. It can be said that the ancient Liupan Mountain "Mountain flowers" changed the fate of Wang Luobin, or that this is deeply rooted in the Northwest Plateau folk songs achievements of his brilliant art.

As the "Mountain flower" expression for the rap, that is, the so-called "verbal" rather than "written", therefore, "Mountain flower" heritage mostly by virtue of the local people's mouth, did not form a rich text Record, which also makes the "mountain flowers" and many other traditional culture, as the times change, but also faced with the lack of success, the difficulties of inheritance embarrassment. "Mountain Flower" famous research scholar, Northern National University Institute of Sociology and Ethnology Professor Wu Yulin believes that the current "Mountain flowers" although some areas in the northwest looks very prosperous, but in fact sing "mountain flowers" are mostly middle-aged Young people do not sing, do not sing "mountain flowers"; sing "mountain flowers" are mostly no cultural or cultural level of people, there are people who cannot sing "mountain flowers"; sing "Mountain flowers" of the region are mostly remote and backward, economically underdeveloped areas, more economically developed areas of people will not sing "Mountain flowers." With the rapid development of modern society, "Mountain flowers" is temporary shortage, on the brink of losing the situation.

\section{The Music and Cultural Analysis of "Mountain Flower" in Liupan Mountain}

Liupan Mountain "Mountain flowers" is divided into "whole flower" and "scattered flowers". "Whole flower" has a narrative, the nature of rap, the form of fixed, can be long rap. "Scattered" is the touch of the scene of the improvisation, "men have to worry about singing, women have a sad one", "'flowers' is the heart of the words, do not sing by not their own (already)", lively Romantic, used to express emotions, with a strong flavor of life. "Mountain flowers" singing form solo, duet, also sing. Collective duet composed of four or five singers composed of both sides of the song, each other fun, and humorous, vivid, lively competition, the scene warm and lively. Singing to the high-pitched place, 
piercing the sky, shock stone; sing to the euphemism, then inextricable and commiserative, fascinating.

In the expression of content, Liupan Mountain "Mountain flowers" theme all-encompassing, love, natural scenery, astronomical climate, myths and legends, historical stories, lashing social ugly phenomenon and so on, the vast majority of love songs, true nature, not the slightest artificial. Liupan Mountain "Mountain flowers" through the rich and unique metaphor, profound expression of the pure love between men and women and the Northwest people loyalty to the infinite desire and loyalty. In order to pursue freedom of love and life, the man was so bold and magnificent performance; the woman was faithful and staunch with moral integrity: "If we want the dissolution of our marriage, Liupan Mountain moved to Sichuan", "If you kill both of us, we'll be together as ghosts". However, in this extremely dangerous environment of suffering people often do not get the ideal of love, often ended in tragedy, which is Liupan Mountain " mountain flowers "the most significant features,"ten shares of tears nine Stock sub-drip, a son of accumulate heart who do", "Little sister when the nun, and the second elder brother was monasticism" [5]. Liupan Mountain "Mountain flowers" beauty is beauty in this simple and natural, it is deeply rooted in the fertile land of Liupan Mountain, with its unique charm, subtle expression, and unspeakable mood to the people here to bring a ray of breeze. It is like a spring, and like drizzle, bit by bit moisturizing this piece of yellow land. In the various periods of history, Liupan Mountain flowers with its unique charm and unique performance, affecting the generation after generation of people, so that this piece of barren and magical land glow with amazing power and human glory, inspired the people here with tenacious spirit, in extremely harsh environment in the production and life.

In terms of cultural values, Liupan Mountain "Mountain flowers" is an important part of the world's intangible cultural heritage and an indispensable cultural treasure for the people of the world. "Mountain flowers" to take the word and pronunciation are highly regional characteristics, the full integration of the Ningxia region of the language features and pronunciation characteristics, the form of the Liupan Mountain area by the traditional folk songs, such as: "such a large window so big door , So big girl does not give people, mother is bad conscience "in the "this" pronunciation is Liupan Mountain area unique hometown zhi", "Mountain flowers" in the geographical pronunciation of the help, sing up more catchy, distinctive and pleasing quality, but also very original. In addition, Liupan Mountain's "Mountain flowers" compared with other traditional culture more dynamic, because the "Mountain flower" expression is through the local people's mouth-minded, many times in the process of production and life due to the atmosphere and appropriate Improvisation creation, by calling their own memories of the tunes and lyrics, combined with their own singing style, production and life content, then the mood and the environment to adapt, the formation of dynamic changes in the melody and melody, which deduce a different version, and thus Liupan Mountain "Mountain flowers" compared to other forms of music, the more local people's daily production and life, showing its unique vitality and vitality, for its cultural values and artistic charm to add a heavy color.

In the style of color, Liupan Mountain "Mountain flower" is the traditional folk songs and "flowers" of the comprehensive derivative art, which expresses the ordinary working people's daily work and life, for example, the working people in daily work, In order to relieve the tiredness and monotony in the process of doing farm work or grazing, usually hum on a "Mountain flowers", on the one hand can express their own feelings of the current situation, have the meaning of self-entertainment; on the one hand by inserting songs in labor, to resolve the work of the process of depression, to enhance their enthusiasm for work, pass the time. Therefore, the "Mountain flower" unique style of music fully reflects the local people's living habits, social background, multicultural, folk customs, mostly in the form of lyrical short songs presented and spread, the use of angle and angle, its melody relative smooth and soft, rhythm for the second shot, three beat or overlapping beats, to deduce a catchy, easy to learn to sing, familiar wild mountain song.

In the music structure, Liupan Mountain "Mountain flowers" music structure is mostly a section of the body, and to two, four most typical. Most have a starting sentence as a song; to function words "hey" or "ouch" at the beginning, there is no real, only raised the role of height; there is no fixed time limit. Followed by the next sentence (the sentence has a different lining as a bedding), the middle 
carrying a more fixed "liner" to do the transition, such as "Elder brother's meat", "Ma Lianhua open", "The white peony of the elder brother" and so on, after the end of the sentence is often docked relatively fixed "lining words" to do the end; such as "Shandan safflower open", "my sister yo" and so on. The end of the "lexical" commonly used "Yeah, yo, ha, ye" and so on to do the end, the end of the tail often with a downward portamento; more time to repeat the second sentence once, and then the speed of a little slower end, form a complete paragraph that combines upper and lower sentences + "lining sentence" [6]. "Mountain flowers" of the entire music structure is simple and easy to remember, flexibility, which is "Mountain flowers" can become popular local "Pop music" one of the important reasons.

In the aspect of cultural inheritance, the Liupan Mountain "Mountain flowers" has a long history, and it fully expresses the production and life development of the people in Ningxia area in the form of folk songs. It has a profound social background and culture. As for the culture of the Liupan Mountain in Ningxia, the "Mountain flower" is an important carrier and figurative expression of the regional social culture. For example, the Ningxia area in the Han and Tang Dynasties social has many nationalities, Qiang, Rong family, Tibetan, Mongolian, Han, Hui and other ethnic groups in the social, in the course of time together, forming a small settlement, social distribution acommunity, multi-ethnic social blend will inevitably bring about multi religious and folk customs, life habits, mode of production, and the formation of continuous running and multi-cultural blend. In the Liupan Mountain region, due to the integration of multi-cultural, regional cultural complex, mainstream culture such as farming culture and the nomadic culture, business culture, therefore, in the historical period of the Liupan Mountain "Mountain flowers" mostly reflect the social situation and the mainstream culture under the people's production and life, and at the same time, the "Mountain flowers" as a historical and modern bridge and media, to provide opportunities for future generations of people, through the "Mountain flowers" to restore and it facilitates the prosperous Han and Tang Ningxia Liupan Mountain area living environment and life mood, enjoy surging tide of historical development of social culture.

\section{Conclusion}

Ningxia Liupan Mountain is the ancient Silk Road must be the main road, is the northern minority and the Central Plains blend area, both by the profound influence of the Central Plains culture, but also inclusive of the western region of the cultural essence of the nation, where the culture To the Hui-based, the national culture blend, infiltration of the diverse styles, which makes Liupan Mountain "Mountain flowers" has a clear geographical characteristics and unique charm. This paper expounds the relationship between music and culture of "mountain flower" from the aspects of expression content, cultural value, music structure, style color and cultural inheritance, which is of great reference value to the protection and inheritance of "Mountain flower" in Liupan Mountain.

\section{Acknowledgements}

Zhang Xiangyong, male (1978.4 ----), Luohe City, Henan Province, associate professor, doctor in reading, research direction: art, piano, piano teaching. Address: Ningxia, Yinchuan, Music and Dance Academy, North University for Nationalities. Mobile phone 13269228216

\section{References}

[1] Journal of Ningxia University (Humanities and Social Sciences), 2013, (01): 126-129. [J]. Journal of Ningxia University (Humanities and Social Sciences), 2013, (01): 126-129.

[2] Jiuwu Sun. Ningxia Liupan Mountain "Mountain flower" music and cultural relations [J]. Art evaluation, 2017, (02): 45-48 +23.

[3] Junjie Ma. Ningxia Liupan Mountain "Mountain flower" metaphor in the cognitive rationale and cultural significance [J]. National Art, 2014, (02): 48-51. 
[4] Yufang Tao. Liupan Mountain flower cultural and ecological protection area construction research [J] .National Sciences, 2011, (05): 153-157.

[5] Nan Yan. Ningxia mountain flower music and structure analysis [J]. Science and Technology Guide (mid-term), 2012, (12): 138-139.

[6] Henghui Ma, Xiaobing Lu. On Liapan Mountain flowers of the intangible cultural heritage characteristics [J]. Famous appreciation, 2012, (30): 138-139. 